\title{
El aprovechamiento de la fauna en el interior del bosque durante el Holoceno temprano y medio. El caso del sitio Población Anticura (provincia de Río Negro, Argentina)
}

\section{(4) Mercedes G. Fernández*}

Fecha de defensa: 5 de Julio de 2017

Director: Dr. Pablo M. Fernández

Jurados: Dres. Carlos Belloti López de Medina

y Diego Rindel

En los últimos años se han realizado avances en el conocimiento de la subsistencia de los cazadores recolectores que habitaron los ambientes boscosos del norte de Patagonia durante el Holoceno temprano y medio (Dillehay, 1997; Hajduk, Albornoz y Lezcano, 2004; Lezcano, Hajduky Albornoz, 2010; Velásquez y Adán, 2004, entre otros). Estos conocimientos provienen de tres sitios, Monte Verde (Dillehay, 1997), Marifilo 1 (García Pérez, 2005: Velásquez y Adán, 2004) y Alero El Trébol (Hajduk et al., 2004; Lezcano et al., 2010). De acuerdo con la composición taxonómica registrada en los últimos sitios, los principales recursos fueron el huemul (Hippocamelus bisulcus), el guanaco (Lama guanicoe) y el pudú (Pudu puda) mientras que en Monte Verde y El Trébol se registró la caza o el carroñeo de fauna extinta (Dillehay, 2000; Hajduk et al., 2004; Lezcano et al., 2010). Sin embargo, más allá de la representación taxonómica registrada en estos sitios aún se desconocen las modalidades de aprovechamiento de las presas en los ambientes boscosos, entendidas como el proceso global de explotación de un animal. A ello se suma el escaso desarrollo de un enfoque tafonómico que permita diferenciar los conjuntos óseos generados por los seres humanos de aquellos producidos por otros agentes. Por ello el objetivo de esta tesis fue determinar las modalidades de aprovechamiento (sensu Mengoni Goñalons, 1999) de los recursos faunísticos durante el Holoceno temprano y medio en el interior del bosque norpatagónico.

Con este propósito se analizaron los conjuntos óseos recuperados en el sitio Población Anticura localizado en el valle del río Manso inferior, sudoeste de la provincia de Río Negro, datados entre 8200-7200 años ${ }^{14} \mathrm{C} \mathrm{AP}$ (niveles 24 a 17) y 4700 años ${ }^{14} \mathrm{C} \mathrm{AP}$ (niveles 16 y 15). El sitio se emplaza en un ambiente de bosque mixto de ciprés (Austrocedrus chilensis) y coihue (Nothofagus dombeyi) en la ladera baja del Cerro Foyel (Fernández y Carballido Calatayud, 2015).

* Instituto Nacional de Antropología y Pensamiento Latinoamericano (INAPL). 3 de febrero 1378 (CP C1426BJN) Ciudad Autónoma de Buenos Aires, Argentina. E-mail: fernandez_mercedesgrisel@hotmail.com
El análisis se realizó desde un enfoque zooarqueológico y tafonómico apoyado en la Ecología Evolutiva, que postula que el proceso evolutivo sucede en un contexto ecológico y que los eventos evolutivos ocurren debido a la interacción de los organismos con el ambiente (Hutchinson, 1965). En este sentido, el ambiente y la estructura de sus recursos son aspectos fundamentales al momento de analizar las decisiones humanas respecto de su subsistencia.

Se empleó la metodología aceptada en zooarqueología correspondiente a la identificación anatómica y taxonómica, la determinación de clases de edad y el análisis de las modificaciones óseas relacionadas con agentes y procesos naturales y con el aprovechamiento humano. Las medidas de cuantificación fueron aquellas utilizadas para estimar la abundancia taxonómica y anatómica; la intensidad y extensión de la fragmentación y aquellas destinadas a evaluar la representación de partes esqueletarias en función de la anatomía económica de las presas (ver por ejemplo, Binford, 1984; Lyman, 1994; Mengoni Goñalons, 1999).

Para cumplir con el objetivo de trabajo, se propusieron cuatro objetivos específicos que incluyeron la identificación de las especies presentes en el sitio, la evaluación de las historias de acumulación y preservación de los conjuntos óseos, diferenciando entre las especies aprovechadas por los seres humanos de aquellas cuya presencia en el registro arqueológico derivase de la acción de otros agentes y procesos, la determinación de las estrategias de obtención, transporte, procesamiento, consumo y descarte de las presas y, por último, la exploración de posibles variaciones temporales en las modalidades de aprovechamiento comparando los conjuntos del Holoceno temprano y los del Holoceno medio.

Dado que sólo a partir de los 1600 años ${ }^{14} \mathrm{C}$ AP hay indicios de una mayor permanencia de los grupos humanos en el bosque mixto norpatagónico (Fernández, Carballido Calatayud, Bellelli y Podestá, 2013), se propuso a modo de hipótesis que durante el Holoceno temprano y medio, pequeños grupos de cazadores-recolectores visitaron el sitio Población Anticura durante cortas estadías y, debido al desconocimiento del ambiente, desarrollaron una estrategia no selectiva de aprovechamiento de las presas disponibles sin solución de continuidad durante 
los dos lapsos como resultado de una etapa exploración del área (sensu Borrero, 1994-1995). Ello implicó la obtención de pocas presas con una ausencia de selección por sexo y edad y la falta de redundancia ocupacional habría dado lugar a una alternancia con carnívoros como zorros (Lycalopex sp.), pumas (Puma concolor) y aves rapaces, quienes actuaron como agentes modificadores $y$ formadores del registro.

En los niveles datados en el Holoceno temprano, el conjunto está dominado por los restos de zorro, seguido en orden de importancia por huemul y luego por pudú. Artiodactyla y Camelidae incluyeron especímenes que no pudieron determinarse a nivel de especie pero que en base a su tamaño y a sus características morfológicas pudieron asignarse a un orden o familia. También se registraron unos pocos restos de Aves. En el Holoceno medio también predominan los restos de zorro, seguido en orden de importancia por el pudú y el huemul, que exhiben proporciones casi idénticas. El puma está representado por un sólo espécimen. La elevada proporción de marcas de carnívoros (más del 50\%) que exhiben los huesos de todos los taxones sugiere que éstos constituyeron el principal agente tafonómico que incidió en la incorporación y transformación de los conjuntos en ambos períodos. No obstante, se determinaron huellas relacionadas con el aprovechamiento humano en especímenes de huemul y zorro en el conjunto del Holoceno temprano y de huemul, zorro y pudú en el Holoceno medio.

Dado que los perfiles de partes esqueletarias se encuentran fuertemente afectados por la actividad de los carnívoros (modificaciones por mascado y/o digestión), la principal línea de evidencia utilizada para recrear el procesamiento y consumo de las presas fue el examen de las huellas de corte y percusión y la fragmentación. Así, el análisis sugiere que durante el Holoceno temprano y medio, el sitio habría funcionado como lugar de procesamiento final y consumo in situ (sensu Lyman, 1994) de los huemules cazados en las cercanías del sitio. El aprovechamiento estuvo orientado al consumo de la carne y a la extracción de la grasa medular. En el caso del zorro, las huellas sugieren un posible uso artefactual de los huesos durante el Holoceno temprano, sumadas a evidencias de consumo cárnico durante el Holoceno medio. El pudú habría sido aprovechado por su carne pero sin descartar el posible uso de sus huesos como materia prima para la confección de artefactos.

Los resultados alcanzados indican que las especies aprovechadas por los cazadores recolectores durante el Holoceno temprano fueron el huemul y el zorro, incorporando el pudú en el Holoceno medio. El aprovechamiento de especies disponibles en el bosque se dio mediante una estrategia no selectiva durante visitas esporádicas y breves de pequeños grupos humanos en una etapa de exploración del bosque que dio lugar a la alternancia ocupacional con los carnívoros del área.

La importancia de este enfoque radica principalmente en que permite ir más allá de las listas de especies presentes en los sitios para ponderar con mayor precisión la importancia de los recursos. Si bien el zorro predomina en los conjuntos de ambos lapsos, el huemul presenta más evidencias de explotación. De ello se desprende que es necesaria la realización de análisis tafonómicos que permitan evaluar si los conjuntos óseos se relacionan con la actividad humana y también que permitan ponderar la magnitud de dicha actividad, es decir, cuánto del comportamiento humano del pasado ha quedado impreso en los huesos. Esto es fundamental si deseamos conocer cómo fue la relación entre los seres humanos y la fauna en el pasado.

\section{Referencias citadas}

" Binford, L. (1984). Faunal Remains from Klasies River Mouth. Orlando: Academic Press.

" Borrero, L. (1994-1995). Arqueología de la Patagonia. Palimpsesto. Revista de Arqueología, 4, 9-69.

" Dillehay, T. (1997). Monteverde. A Late Pleistocene Settlement in Chile. Washington: Smithsonian Institution Press.

"Dillehay, T. (2000). The Settlement of the Americas. A New Prehistory. Nueva York: Basic Books.

» Fernández, P. M. y Carballido Calatayud, M. (2015). Armas y presas. Técnicas de caza en el interior del bosque patagónico. Relaciones de la Sociedad Argentina de Antropología, XL(1), 279-301.

» Fernández, P. M., Carballido Calatayud, M., Bellelli, C. y Podestá, M. M. (2013). Tiempo de cazadores. Cronología de las ocupaciones humanas en el valle del río Manso inferior (Río Negro). En A. F. Zangrando, R. Barberena, A. Gil, G. Neme, M. Giardina, L. Luna, C. Otaola, S. Paulides, L. Salgán y A. Tivoli (Eds.), Tendencias TeóricoMetodológicas y Casos de Estudio en la Arqueología de la Patagonia (pp. 167-175). San Rafael: Museo de Historia Natural de San Rafael.

" García Pérez, C. (2005). Estrategias de movilidad de cazadores recolectores durante el Período Arcaico en la Región del Calafquén, sur de Chile. (Tesis de Licenciatura inédita), Universidad de Chile, Chile.

" Hajduk, A., Albornoz, A. y Lezcano, M. (2004). El "Mylodon" en el patio de atrás. Informe preliminar sobre los trabajos en el sitio El Trébol, ejido urbano de San Carlos de Bariloche, Provincia de Río Negro. En M. T. Civalero, P. M. Fernández y A. G. Guráieb (Eds.), Contra Viento y Marea. Arqueología de Patagonia (pp. 715- 
731). Buenos Aires: Instituto Nacional de Antropología y Pensamiento Latinoamericano y Sociedad Argentina de Antropología.

» Hutchinson, G. (1965). The Ecological Theater and the Evolutionary Play. New Haven: Yale University Press.

» Lezcano, M., Hajduk, A. y Albornoz, A. (2010). El menú a la carta en el bosque ¿entrada o plato fuerte?: una perspectiva comparada desde la zooarqueología del sitio El Trébol (lago Nahuel Huapi, Pcia. de Río Negro). En M. A. Gutiérrez, M. De Nigris, P. M. Fernández, M. Giardina, A. F. Gil, A. Izeta, G. Neme y H. D. Yacobaccio (Eds.), Zooarqueología a Principios del Siglo XXI: Aportes Teóricos, Metodológicos y Casos de Estudio (pp. 243-257). Buenos Aires: Libros del Espinillo.
» Lyman, R. (1994). Vertebrate Taphonomy. Cambridge: Cambridge University Press.

» Mengoni Goñalons, G. (1999). Cazadores de Guanacos de la Estepa Patagónica. Buenos Aires: Sociedad Argentina de Antropología.

»Velásquez, H. y Adán, L. (2004). Alero Marifilo 1: Evidencias arqueofaunísticas para entender las relaciones hombre y bosques templados en los sistemas lacustres cordilleranos del Centro Sur de Chile. En M. Civalero, P. Fernández y A. Guráieb (Eds.), Contra Viento y Marea. Arqueología de Patagonia (pp. 507-520). Buenos Aires: Instituto Nacional de Antropología y Pensamiento Latinoamericano y Sociedad Argentina de Antropología. 